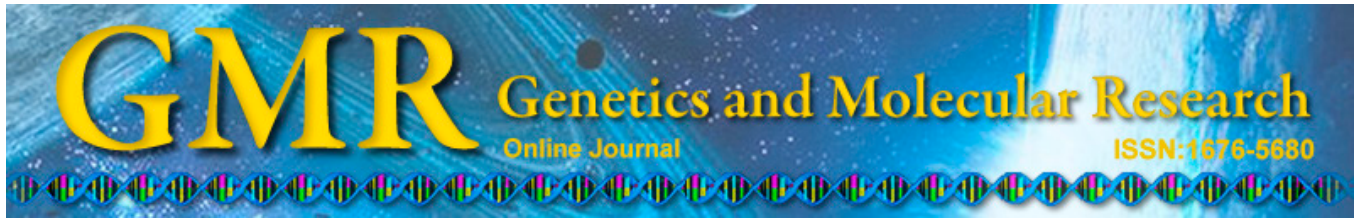

\title{
Correlation between $M T P-493 G>T$ polymorphism and non-alcoholic fatty liver disease risk: a meta-analysis
}

\author{
L. Li, S.J. Wang, K. Shi, D. Chen, H. Jia and J. Zhu \\ Department of Emergency, \\ Corresponding author: J. Zhu \\ E-mail: cmu4h_zj@163.com \\ Genet. Mol. Res. 13 (4): 10150-10161 (2014) \\ Received November 21, 2013 \\ Accepted June 25, 2014 \\ Published December 4, 2014 \\ DOI http://dx.doi.org/10.4238/2014.December.4.9
}

The Fourth Affiliated Hospital of China Medical University, Shenyang, China

\begin{abstract}
Several studies have found that microsomal transfer protein (MTP) may be important in the development and progression of non-alcoholic fatty liver disease (NAFLD). In this meta-analysis, we evaluated the relationships between a common polymorphism $(-493 \mathrm{G}>\mathrm{T}$, rs1800591 $\mathrm{G}>\mathrm{T})$ in the MTP gene and NAFLD risk. The PubMed, CISCOM, CINAHL, Web of Science, Google Scholar, EBSCO, Cochrane Library, and CBM databases were searched for relevant articles published before October 1, 2013 without any language restrictions. Meta-analysis was conducted using the STATA 12.0 software. Crude odds ratios (ORs) with $95 \%$ confidence intervals $(95 \% \mathrm{CIs})$ were calculated. Eleven case-control studies were included in this meta-analysis. A total of 636 NAFLD patients and 918 healthy control subjects were examined in this meta-analysis. Our results indicate that the MTP $-493 \mathrm{G} / \mathrm{T}$ polymorphism increases the risk of NAFLD ( $\mathrm{G}$ allele $v s \mathrm{~T}$ allele: $\mathrm{OR}=1.39,95 \% \mathrm{CI}=1.17-1.65, \mathrm{P}<0.001$; $\mathrm{GG}+\mathrm{GT} v s \mathrm{TT}: \mathrm{OR}=1.46,95 \% \mathrm{CI}=1.02-2.09, \mathrm{P}=0.038$, respectively). Subgroup analyses indicated that the MTP $-493 \mathrm{G} / \mathrm{T}$ polymorphism was associated with an increased risk of NAFLD in population-based,
\end{abstract}


hospital-based, polymerase chain reaction-restriction fragment length polymorphism (PCR-RFLP), and large sample-size subgroups under the allele and dominant models (all $\mathrm{P}<0.05$ ). However, we found no association between non-PCR-RFLP polymorphism and small samplesize subgroups (all $\mathrm{P}>0.05$ ). Our findings indicate that the MTP $-493 \mathrm{G} /$ $\mathrm{T}$ polymorphism may contribute to the development of NAFLD. Thus, the MTP $-493 \mathrm{G} / \mathrm{T}$ polymorphism may be a biomarker for the early detection of NAFLD.

Key words: Meta-analysis; Microsomal transfer protein; Non-alcoholic fatty liver disease; Polymorphism

\section{INTRODUCTION}

Non-alcoholic fatty liver disease (NAFLD) is the most common form of chronic liver disease worldwide and can progress to more severe forms of diseases such as cirrhosis or liver cancer (Wong et al., 2011). With the increasing obesity pandemic, the prevalence of NAFLD has approximately doubled over the past decade (Fan and Farrell, 2009). NAFLD is considered to be the hepatic manifestation of metabolic syndrome, affecting an estimated $2-3 \%$ of the general population and up to $37 \%$ of morbidly obese patients (Patton et al., 2010). Previous studies reported that obesity, hypoadiponectinemia, hyperinsulinemia, and diabetes may be causally related to NAFLD development (Pagano et al., 2005; Yoon et al., 2005; Poniachik et al., 2006; Yoneda et al., 2007; Shimabukuro et al., 2013). In general, NAFLD is a multifactorial disease induced by complex interactions between nutritional factors, lifestyle choices, and genetic determinants (Malaguarnera et al., 2009). Previous studies suggested that genetic factors play an important role in NAFLD etiology by altering hepatic lipid metabolism in different tissues in humans (Day, 2006; Duvnjak et al., 2009; Dongiovanni et al., 2010; Alisi et al., 2012).

Microsomal transfer protein (MTP), a lipid transfer protein involved in apoB-lipoprotein assembly, is localized to the endoplasmic reticulum in hepatocytes and enterocytes (Hussain et al., 2012). Lower hepatic expression of MTP plays a crucial role in NAFLD development (Dowman et al., 2010). Genetic and epigenetic alterations in the MTP gene may reduce its circulating concentrations and lead to inadequate formation of very low-density lipoproteins and chylomicrons, which may increase degradation of apoB-lipoprotein, resulting in dysregulation of hepatic lipid metabolism; this would explain the inter-individual differences in NAFLD risk (Di Filippo et al., 2012). Based on the results of previous studies, we hypothesized that MTP gene polymorphisms modulate individual differences in hepatic lipid metabolism and increase an individual's susceptibility to NAFLD.

The human MTP gene is located on chromosome 4q24 and consists of 18 exons and 17 introns, spanning approximately 55-60 kb (Hashemi et al., 2011). Although a large number of single-nucleotide polymorphisms in the MTP gene have been identified, $-493 \mathrm{G}>\mathrm{T}$ (rs1800591) is one of the most common and widely investigated polymorphisms (Mirandola et al., 2009; Siqueira et al., 2012). The MTP $-493 \mathrm{G}>\mathrm{T}$ polymorphism results from a G>T substitution in the intron region of NM_000253.2. Several previous studies have suggested that the MTP $-493 \mathrm{G}>\mathrm{T}$ polymorphism plays critical roles in the pathogenesis of NAFLD (Namikawa et al., 2004; Musso et al., 2007; Gambino et al., 2007; Zampino et al., 2008; Mirandola et al., 2009; Oliveira et al., 2010; Musso et al., 2010; El-Koofy et al., 2011; Siqueira et al., 2012). 
However, there are contradictory data concerning the role of the MTP $-493 \mathrm{G}>\mathrm{T}$ polymorphism in NAFLD development (Petit et al., 2006; Carulli et al., 2009). The controversial findings are likely related to the effects from other genes, environmental effects, or different methods of classification, sample sizes, and study design. Therefore, we performed a meta-analysis to provide insight into the relationship between the MTP $-493 \mathrm{G}>\mathrm{T}$ polymorphism and NAFLD risk.

\section{MATERIAL AND METHODS}

\section{Search strategy}

The PubMed, CISCOM, CINAHL, Web of Science, Google Scholar, EBSCO, Cochrane Library, and CBM databases were searched for relevant articles published before October 1, 2013 without language restrictions. The following keywords and MeSH terms were used: ("SNP" or "mutation" or "genetic polymorphism" or "variation" or "polymorphism" or "single nucleotide polymorphism" or "variant") and ("non-alcoholic fatty liver disease" or "nonalcoholic steatohepatitis" or "NAFLD" or "fatty liver") and ("microsomal triglyceride transfer protein" or "MTP" or "MTP - 1 "). We also performed a manual search of the reference lists of the relevant articles to identify other potential articles.

\section{Selection criteria}

The included studies were required to meet all of the 5 following criteria: 1 ) the study design must be a clinical cohort or case-control study; 2) the study must relate to the relationships between MTP -493G>T polymorphism and NAFLD risk; 3) all patients must conform to the diagnostic criteria of NAFLD; 4) the study must provide sufficient data on the frequencies of allele or genotype; 5) the genotype distribution of healthy control subjects must conform to Hardy-Weinberg equilibrium (HWE). Studies that did not meet the criteria were excluded. If the authors published several studies using the same subjects, the most recent publication or the publication with the largest sample size was included.

\section{Data extraction}

Relevant data were systematically extracted from all included studies by 2 independent researchers using a standardized form. The researchers collected the following data: language of publication, publication year, the first author's surname, geographical location, design of study, sample size, the source of the subjects, allele frequencies, source of samples, genotyping method of single-nucleotide polymorphism, frequencies of allele or genotype, and evidence of HWE in healthy control subjects.

\section{Quality assessment}

Methodological quality was independently assessed by 2 independent researchers according to the Newcastle-Ottawa Scale (NOS) criteria (Stang, 2010). The NOS criteria includes 3 aspects: 1) subject selection: $0-4 ; 2$ ) comparability of subject: $0-2$; and 3 ) clinical outcome: $0-3$. NOS scores range from $0-9$, and a score $\geq 7$ indicates good quality. 


\section{Statistical analysis}

The STATA version 12.0 (Stata Corp; College Station, TX, USA) software was used for the meta-analysis. We calculated the crude odds ratios (OR) or standardized mean difference with their $95 \%$ confidence intervals $(95 \% \mathrm{CIs})$ to evaluate the relationships under 5 genetic models: allele model (G allele $v s$ T allele), dominant model (GG+GT $v s \mathrm{TT})$, recessive model (GG vs GT+TT), homozygous model (GG vs TT), and heterozygous model (GG vs GT). The $Z$ test was used to estimate the statistical significance of pooled statistics. Cochran's $Q$-statistic and $I^{2}$ tests were used to evaluate potential heterogeneity between studies (Zintzaras and Ioannidis, 2005). If the $Q$-test showed a $\mathrm{P}<0.05$ or $I^{2}$ was $>50 \%$, indicating significant heterogeneity, the random-effects model was conducted; otherwise, the fixed-effects model was used (Peters et al., 2006). To evaluate the influence of single studies on the overall estimate, sensitivity analysis was performed. We conducted Begger's funnel plots and Egger's linear regression tests to investigate publication bias (Peters et al., 2006).

\section{RESULTS}

\section{Baseline characteristics of studies included}

Initially, the searched key words identified 47 articles. We reviewed the titles and abstracts of all articles and excluded 20 articles; full-texts and data integrity were also reviewed, and 16 additional articles were excluded. Finally, 11 case-control studies that met all of the inclusion criteria were included in this meta-analysis (Namikawa et al., 2004; Petit et al., 2006; Gambino et al., 2007; Zampino et al., 2008; Mirandola et al., 2009; Carulli et al., 2009; Oliveira et al., 2010; Musso et al., 2007, 2010; El-Koofy et al., 2011; Siqueira et al., 2012). Publication years ranged from 2004-2012. Figure 1 shows the selection process of eligible articles. The distribution of the number of topic-related articles in the electronic database over the last decade is shown in Figure 2. A total of 1554 subjects were involved in this meta-analysis, including 636 NAFLD patients and 918 healthy controls. Overall, 6 studies were conducted in Caucasians, 4 in non-Caucasians, and 1 in a mixed population. Five studies used population-based (community populations) controls, while the other 6 studies used

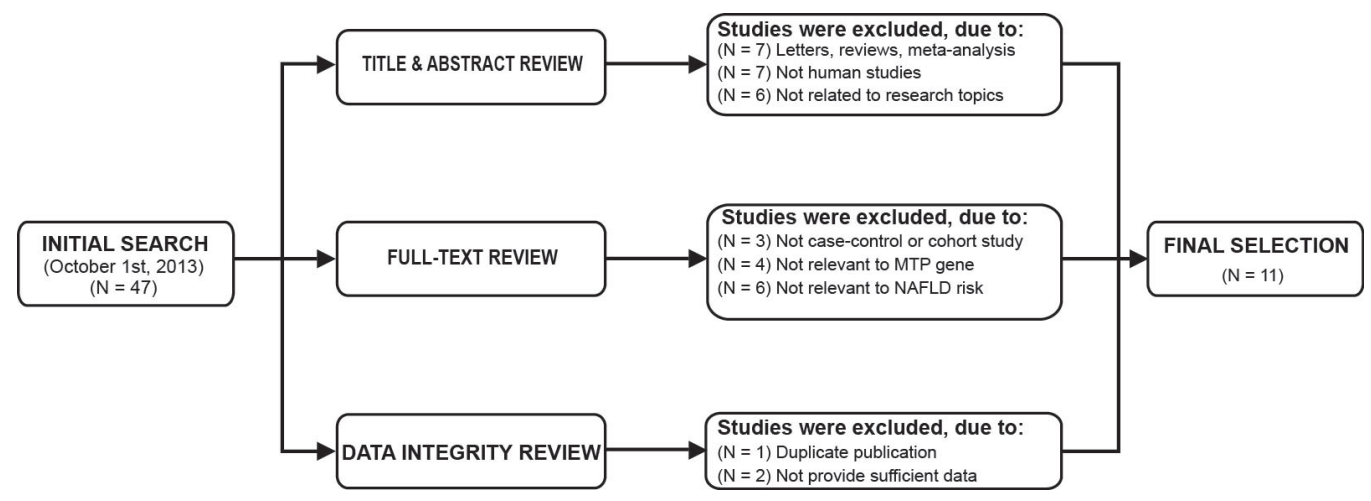

Figure 1. Flow chart of literature search and study selection. Eleven case-control studies were included in this meta-analysis. 


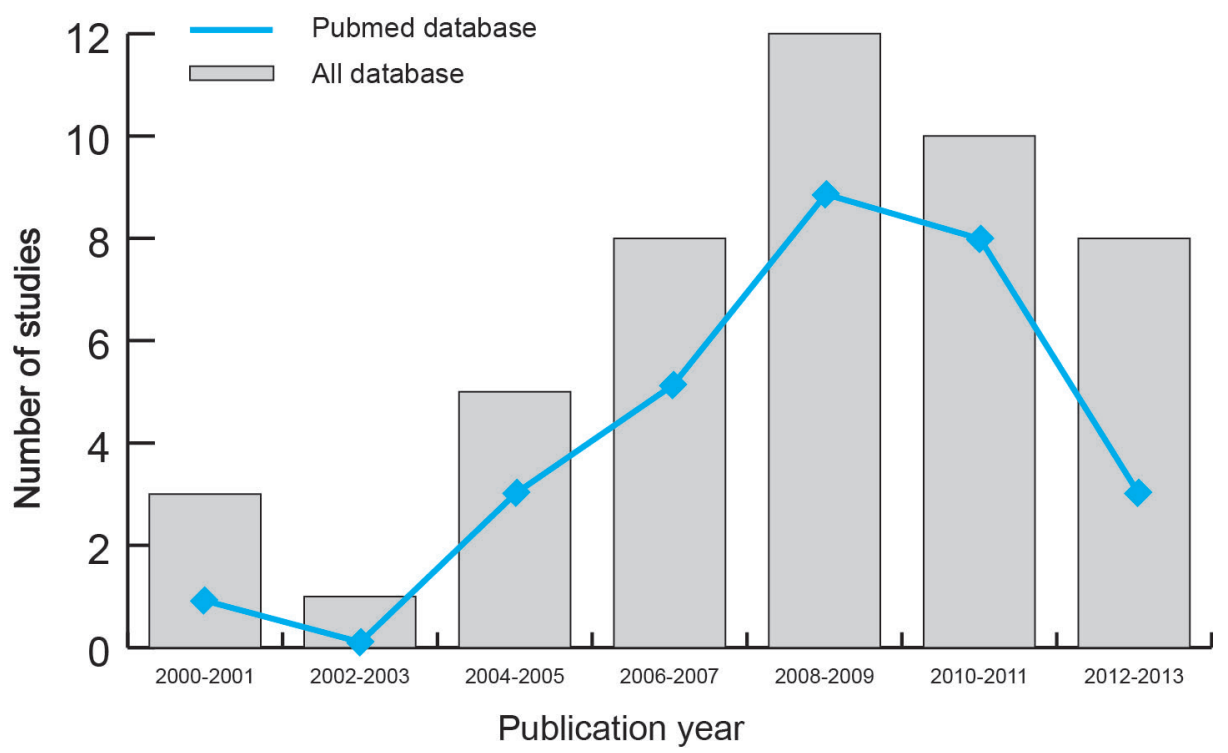

Figure 2. Distribution of the number of topic-related literatures in the electronic database over the past decade.

hospital-based controls. The classical polymerase chain reaction-restriction fragment length polymorphism (PCR-RELP) method was performed in 8 studies, while 2 studies used the direct DNA sequencing method, and the other study used the TaqMan method. Genotype frequencies of controls were all in HWE (all P $>0.05$ ). NOS scores of all included studies were $\geq 6$ (moderate-high quality). We summarized the study characteristics and methodological quality in Table 1.

Table 1. Main characteristics and methodological quality of all eligible studies.

\begin{tabular}{|c|c|c|c|c|c|c|c|c|c|c|c|c|}
\hline \multirow[t]{2}{*}{ First author } & \multirow[t]{2}{*}{ Year } & \multirow[t]{2}{*}{ Country } & \multicolumn{2}{|c|}{$\mathrm{N}$} & \multicolumn{2}{|c|}{ Gender $(\mathrm{M} / \mathrm{F})$} & \multicolumn{2}{|c|}{ Age (years) } & \multirow{2}{*}{$\begin{array}{l}\text { Source of } \\
\text { controls }\end{array}$} & \multirow{2}{*}{$\begin{array}{l}\text { Genotyping } \\
\text { method }\end{array}$} & \multirow{2}{*}{$\begin{array}{c}\text { HWE } \\
\text { test }\end{array}$} & \multirow{2}{*}{$\begin{array}{l}\text { NOS } \\
\text { score }\end{array}$} \\
\hline & & & Case & Control & Case & Control & Case & Control & & & & \\
\hline Namikawa et al. & 2004 & Japan & 63 & 150 & $33 / 30$ & $83 / 67$ & $43.6 \pm 16.4$ & $47.1 \pm 15.6$ & PB & PCR-RFLP & 0.536 & 6 \\
\hline Petit et al. & 2006 & France & 39 & 47 & $24 / 15$ & $29 / 18$ & $48.9 \pm 11.4$ & $44.3 \pm 13.2$ & HB & TaqMan & 0.661 & 7 \\
\hline Gambino et al. & 2007 & Italy & 29 & 27 & $24 / 5$ & $23 / 4$ & $39.0 \pm 2.0$ & $35.0 \pm 2.0$ & PB & PCR-RFLP & 0.546 & 7 \\
\hline Musso et al. & 2007 & Italy & 64 & 74 & $50 / 14$ & $60 / 14$ & $48.0 \pm 3.0$ & $52.0 \pm 2.0$ & PB & PCR-RFLP & 0.150 & 8 \\
\hline Zampino et al. & 2008 & Italy & 32 & 70 & $20 / 12$ & $37 / 33$ & $38.0 \pm 4.0$ & $52.0 \pm 4.0$ & HB & PCR-RFLP & 0.258 & 6 \\
\hline Carulli et al. & 2009 & Italy & 114 & 79 & $74 / 40$ & $28 / 51$ & $48.7 \pm 1.3$ & $38.4 \pm 1.3$ & HB & PCR-RFLP & 0.093 & 8 \\
\hline Mirandola et al. & 2009 & Multi-country & 45 & 253 & $34 / 11$ & $134 / 119$ & $41.5 \pm 9.0$ & $47.7 \pm 12.2$ & PB & PCR-RFLP & 0.516 & 7 \\
\hline Musso et al. & 2010 & Italy & 40 & 40 & $27 / 13$ & $28 / 12$ & $43.0 \pm 2.0$ & $42.0 \pm 2.0$ & PB & PCR-RFLP & 0.813 & 6 \\
\hline Oliveira et al. & 2010 & Brazil & 129 & 113 & - & - & - & - & HB & Direct sequencing & 0.901 & 5 \\
\hline El-Koofy et al. & 2011 & Egypt & 15 & 20 & $7 / 8$ & $10 / 10$ & $7.7 \pm 3.5$ & $7.7 \pm 3.5$ & HB & PCR-RFLP & 0.084 & 8 \\
\hline Siqueira et al. & 2012 & Brazil & 66 & 45 & $36 / 30$ & $24 / 21$ & $54.0 \pm 2.0$ & $52.0 \pm 2.0$ & HB & Direct sequencing & 0.655 & 9 \\
\hline
\end{tabular}

$\mathrm{M}=$ male; $\mathrm{F}=$ female; $\mathrm{PB}=$ population-based; $\mathrm{HB}=$ hospital-based; PCR-RFLP = polymerase chain reactionrestriction fragment length polymorphism.

\section{Quantitative data synthesis}

The findings of our meta-analysis regarding the relationships between the MTP $-493 \mathrm{G} / \mathrm{T}$ polymorphism and the risk of NAFLD are shown in Table 2 . The random effects 
model was used because of the existence of significant heterogeneity between studies. Our meta-analysis results revealed that the MTP $-493 \mathrm{G} / \mathrm{T}$ polymorphism may increase the risk of NAFLD (G allele $v s$ T allele: $\mathrm{OR}=1.39,95 \% \mathrm{CI}=1.17-1.65, \mathrm{P}<0.001 ; \mathrm{GG}+\mathrm{GT} v s$ TT: OR $=1.46,95 \% \mathrm{CI}=1.02-2.09, \mathrm{P}=0.038)$ (Figure 3 ).

Table 2. Meta-analysis of the associations between the MTP $-493 \mathrm{G}>\mathrm{T}$ polymorphism and non-alcoholic fatty liver disease risk.

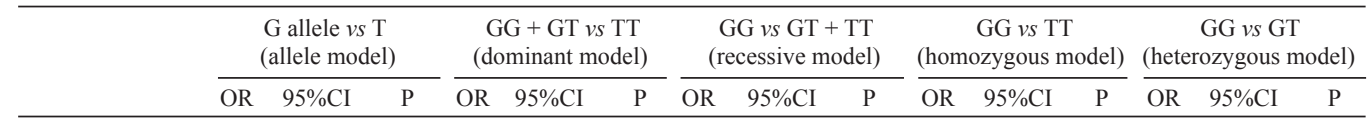

\begin{tabular}{llllllllllllllllll}
\hline Overall & 1.39 & $1.17-1.65$ & $<0.001$ & 1.46 & $1.02-2.09$ & 0.038 & 1.51 & $1.21-1.89<0.001$ & 1.68 & $1.15-2.47$ & 0.007 & 1.50 & $1.14-1.96$ & 0.003
\end{tabular}

Source of controls

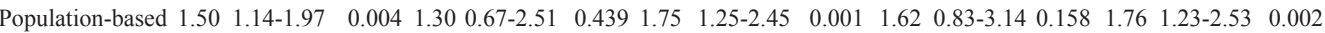
$\begin{array}{lllllllllllllllll}\text { Hospital-based } & 1.32 & 1.06-1.64 & 0.014 & 1.53 & 0.97-2.41 & 0.065 & 1.38 & 0.99-1.94 & 0.060 & 1.70 & 1.04-2.77 & 0.034 & 1.38 & 0.88-2.16 & 0.166\end{array}$ Genotyping method

$\begin{array}{llllllllllllllllll}\text { PCR-RFLP } & 1.47 & 1.19-1.80 & <0.001 & 1.61 & 1.06-2.47 & 0.027 & 1.61 & 1.19-2.16 & 0.002 & 1.80 & 1.14-2.83 & 0.011 & 1.56 & 1.09-2.23 & 0.016\end{array}$

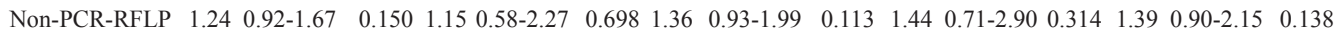
Sample size

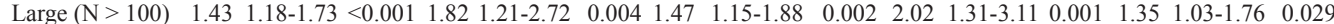

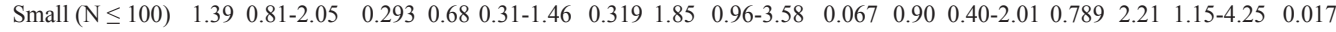

$\mathrm{W}=$ wild-type allele; $\mathrm{M}=$ mutant allele; $\mathrm{WW}=$ wild-type homozygote; $\mathrm{WM}=$ heterozygote; $\mathrm{MM}=$ mutant homozygote; $\mathrm{OR}=$ odds ratio; $95 \% \mathrm{CI}=95 \%$ confidence interval; $\mathrm{SNP}=$ single-nucleotide polymorphism; $\mathrm{PCR}$ $\mathrm{RFLP}=$ polymerase chain reaction-restriction fragment length polymorphism.
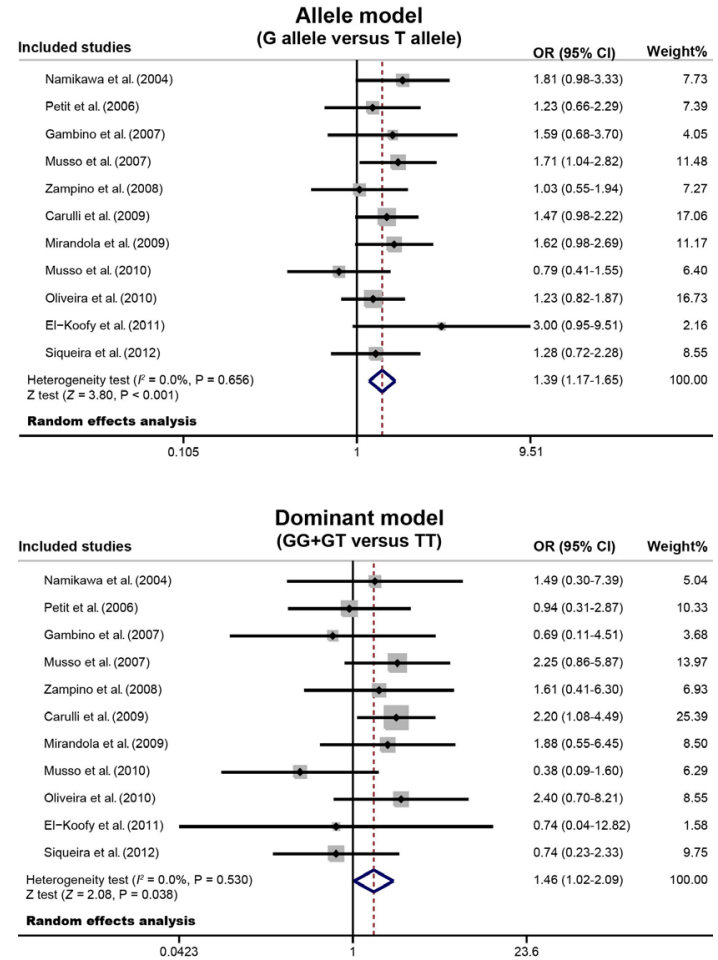

Figure 3. Forest plots for the relationships between the $M T P-493 \mathrm{G}>\mathrm{T}$ polymorphism and NAFLD risk under the allele and dominant models. 
Subgroup and meta-regression analyses were conducted based on the source of controls, genotyping method, and sample size to investigate potential sources of heterogeneity. Subgroup analysis by source of controls showed the MTP $-493 \mathrm{G} / \mathrm{T}$ polymorphism may increase the risk of NAFLD in both the population-based subgroup ( $\mathrm{G}$ allele $v s \mathrm{~T}$ allele: $\mathrm{OR}=1.50$, $95 \% \mathrm{CI}=1.14-1.97, \mathrm{P}=0.004)$ and hospital-based subgroup $(\mathrm{G}$ allele $v s \mathrm{~T}$ allele: $\mathrm{OR}=1.32$, $95 \% \mathrm{CI}=1.06-1.64, \mathrm{P}=0.014)$. Further subgroup analyses based on genotyping method and sample size suggested that the MTP $-493 \mathrm{G} / \mathrm{T}$ polymorphism was associated with an increased NAFLD risk in the PCR-RFLP and large sample-size subgroups under the allele and dominant models (all $\mathrm{P}<0.05$ ); however, no association was observed in the non-PCR-RFLP and small sample-size subgroups (all $\mathrm{P}>0.05$ ) (Figure 4). Meta-regression analyses indicated that none of these potential factors were the main sources of heterogeneity (as shown in Table 3).

The results of sensitivity analysis suggested that no single study influenced the overall pooled ORs (Figure 5). We found no evidence of asymmetry in the Begger's funnel plots (Figure 6). Egger's test did not reveal publication bias (allele mode: $\mathrm{t}=0.47, \mathrm{P}=0.649$; dominant model: $\mathrm{t}=-1.92, \mathrm{P}=0.886$ ).

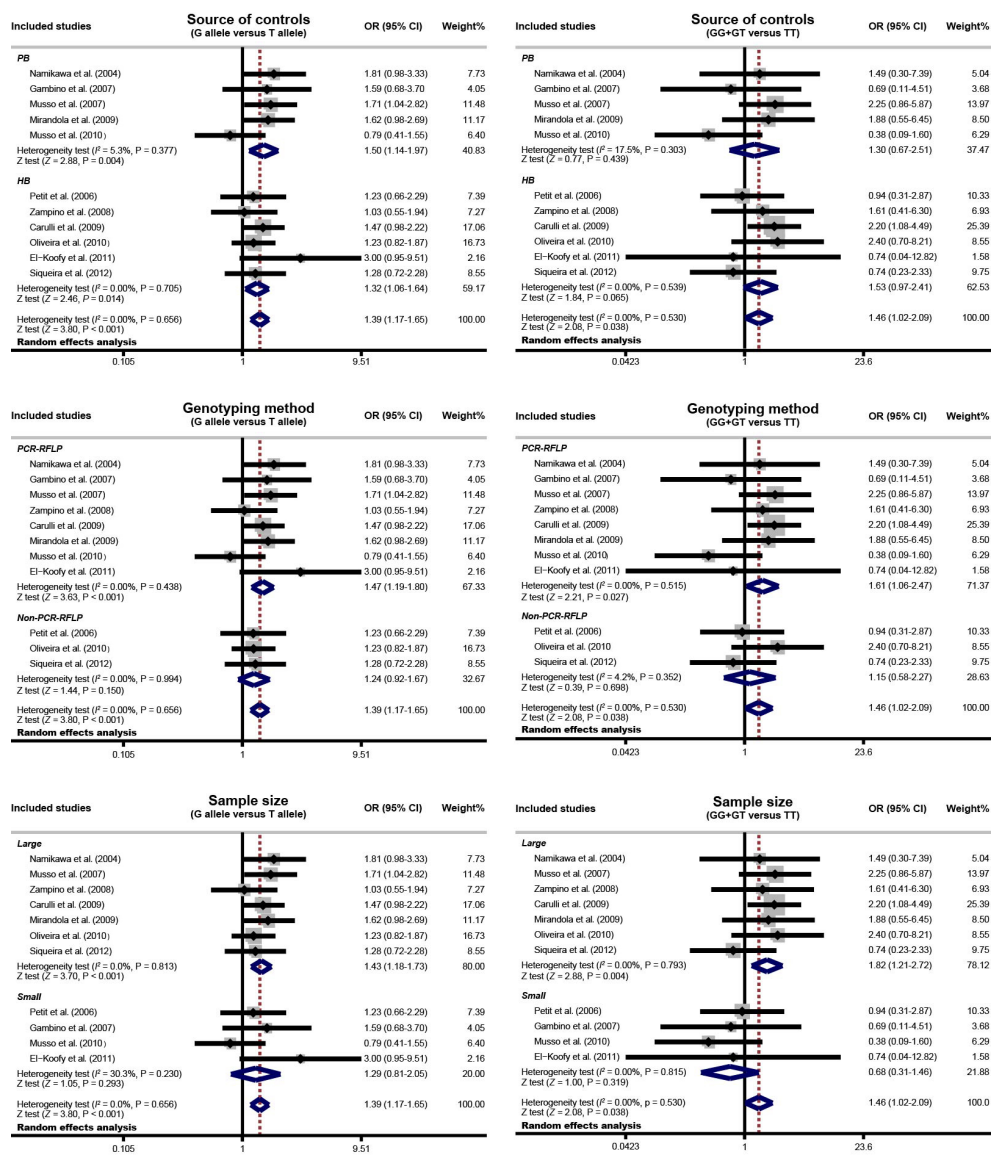

Figure 4. Subgroup analyses of the relationships between the MTP $-493 \mathrm{G}>\mathrm{T}$ polymorphism and NAFLD risk under the allele and dominant models. 
Table 3. Univariate and multivariate meta-regression analyses of potential source of heterogeneity.

\begin{tabular}{|c|c|c|c|c|c|c|}
\hline \multirow[t]{2}{*}{ Heterogeneity factors } & \multirow[t]{2}{*}{ Coefficient } & \multirow[t]{2}{*}{ SE } & \multirow[t]{2}{*}{$Z$} & \multirow[t]{2}{*}{$\mathrm{P}$} & \multicolumn{2}{|c|}{$95 \% \mathrm{CI}$} \\
\hline & & & & & LL & UL \\
\hline \multicolumn{7}{|l|}{ Publication year } \\
\hline Univariate & -0.037 & 0.042 & -0.83 & 0.378 & -0.120 & 0.046 \\
\hline Multivariate & -0.026 & 0.048 & -0.54 & 0.588 & -0.120 & 0.068 \\
\hline \multicolumn{7}{|l|}{ Source of controls } \\
\hline Univariate & -0.128 & 0.176 & -0.73 & 0.466 & -0.473 & 0.217 \\
\hline Multivariate & -0.018 & 0.227 & -0.08 & 0.935 & -0.462 & 0.426 \\
\hline \multicolumn{7}{|l|}{ Genotype method } \\
\hline Univariate & -0.165 & 0.184 & -0.89 & 0.371 & -0.527 & 0.197 \\
\hline Multivariate & -0.112 & 0.229 & -0.49 & 0.624 & -0.561 & 0.336 \\
\hline \multicolumn{7}{|l|}{ Sample size } \\
\hline Univariate & -0.145 & 0.216 & -0.67 & 0.504 & -0.569 & 0.279 \\
\hline Multivariate & -0.165 & 0.218 & -0.76 & 0.448 & -0.592 & 0.262 \\
\hline
\end{tabular}

$\mathrm{SE}=$ standard error; $95 \% \mathrm{CI}=95 \%$ confidence interval; $\mathrm{UL}=$ upper limit; $\mathrm{LL}=$ lower limit.
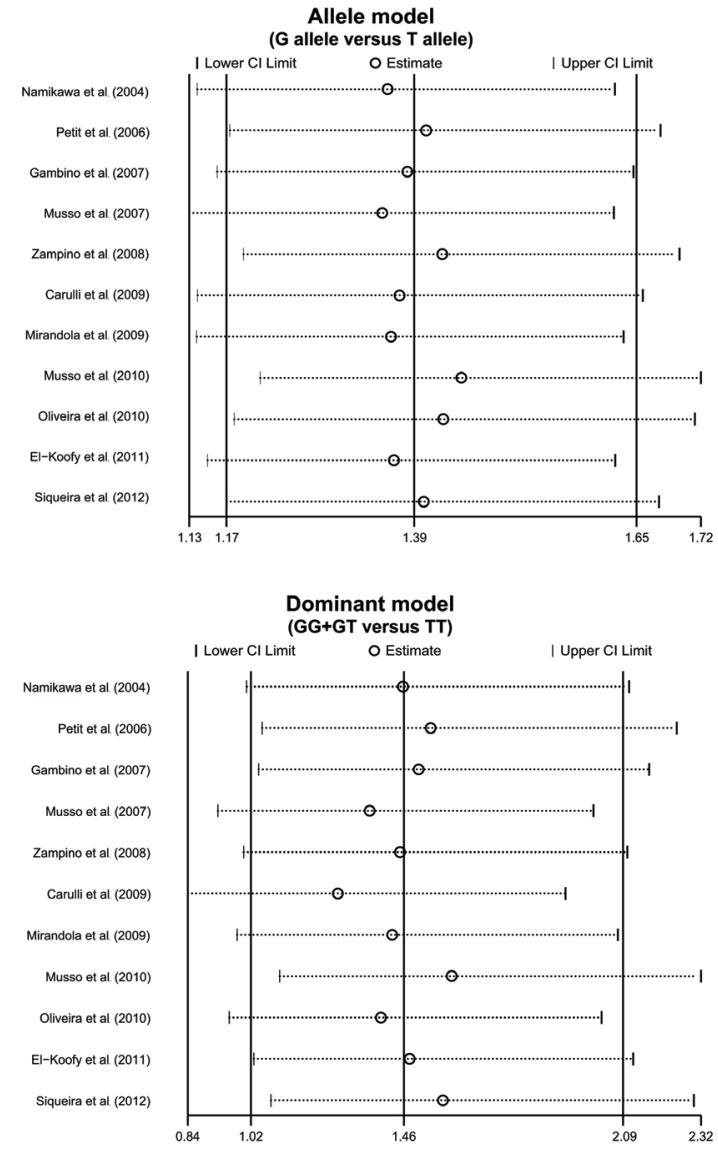

Figure 5. Sensitivity analysis of the summary odds ratio coefficients regarding the relationships between the MTP $-493 \mathrm{G}>\mathrm{T}$ polymorphism and NAFLD risk under the allele and dominant models. The results were computed by omitting each study in turn. Meta-analysis random-effects estimates (exponential form) were used. The two ends of the dotted lines represent the $95 \% \mathrm{CI}$. 

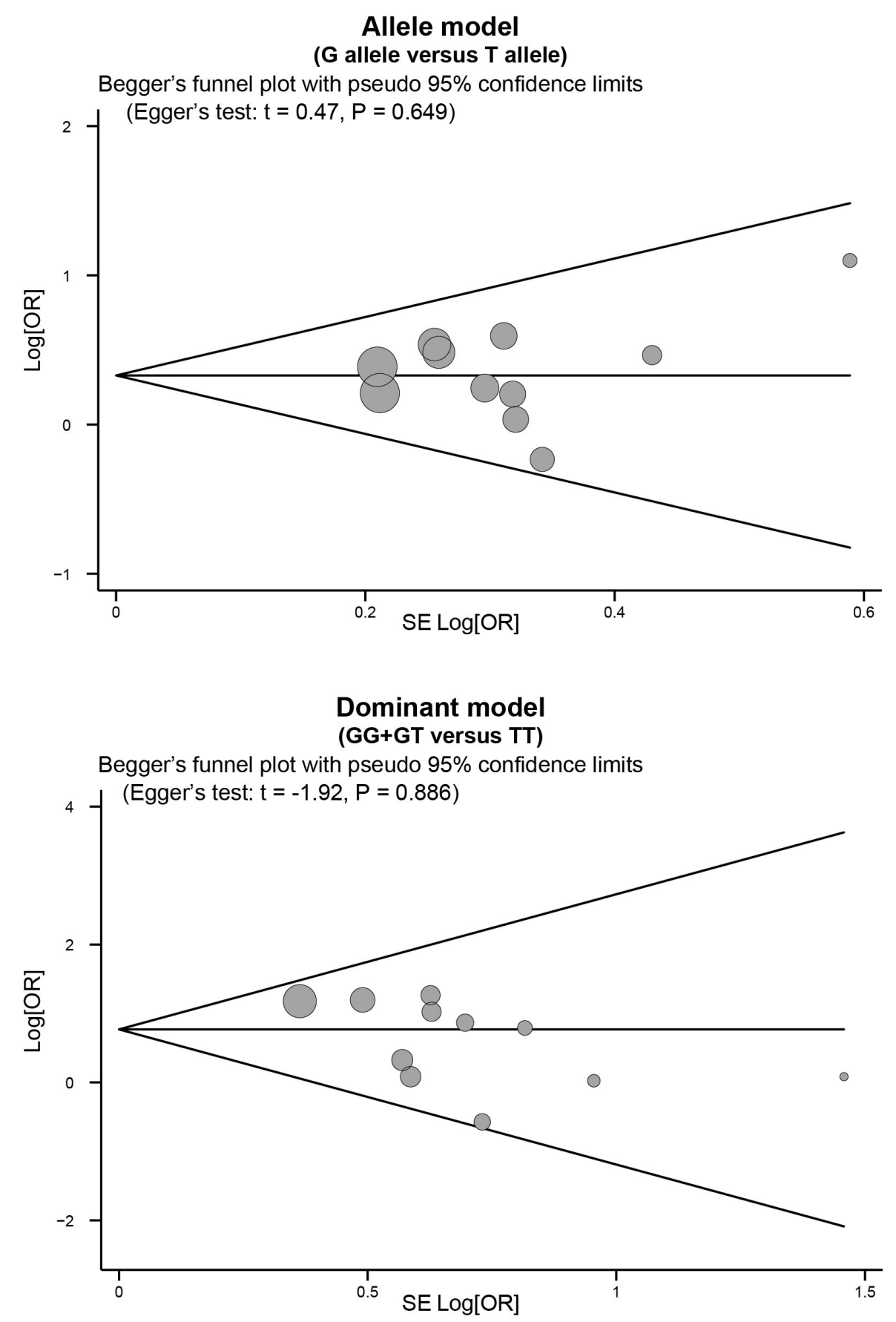

Figure 6. Begger's funnel plot of publication biases regarding the relationships between the $M T P-493 \mathrm{G}>\mathrm{T}$ polymorphism and NAFLD risk under the allele and dominant models. Each point represents a separate study for the indicated association. $\log [\mathrm{OR}]$, natural logarithm of OR. Horizontal line, mean magnitude of the effect. 


\section{DISCUSSION}

NAFLD covers a spectrum of hepatic pathologies ranging from simple steatosis through steatohepatitis to fibrosis and irreversible cirrhosis (Fon Tacer and Rozman, 2011). The prevalence of NAFLD has increased rapidly in parallel with dramatic increases in obesity and diabetes and is becoming the most common liver disease worldwide (Sugihara et al., 2013). Although NAFLD is one of the most common chronic hepatic diseases, its fundamental molecular pathways remain unclear (Tannapfel et al., 2011). Hepatic lipid and lipoprotein abnormalities accompanied by chronic inflammation play a vital role in NAFLD pathogenesis and progression (Fon Tacer and Rozman, 2011). Excessive accumulation of triglycerides in hepatocytes is a hallmark feature of NAFLD (Postic and Girard, 2008). Hepatic triglycerides are normally exported from the liver in the form of very low-density lipoproteins particles, which is mediated through plasma apoB-lipoprotein and MTP (Sun et al., 2012). Lipid transfer activity of MTP is required for the assembly and secretion of apoB-lipoproteins (Liu et al., 2010). Aberrant alterations during MTP synthesis and secretion have been proposed as potential mechanisms underlying the pathogenesis of NAFLD, leading to a decreased capacity for lipid export (Dowman et al., 2010).

Genetic variations in the MTP gene may contribute to an individual's susceptibility to NAFLD (Day, 2010). Common functional polymorphism in the human MTP gene may result in decreased protein production and dysregulation of hepatic lipid metabolism, thus contributing to the development of NAFLD (Pereira et al., 2011). In the present meta-analysis, to investigate whether the MTP $-493 \mathrm{G}>\mathrm{T}$ polymorphism influences an individual's susceptibility to NAFLD, we performed a meta-analysis of 11 independent case-control studies with a total of 636 NAFLD patients and 918 healthy controls. Our meta-analysis results showed that the MTP $-493 \mathrm{G}>\mathrm{T}$ polymorphism was associated with an increased risk of NAFLD, suggesting that this polymorphism is a causative factor in the incidence of NAFLD. Inherited mutations in the MTP gene may be associated with changes in hepatic lipid metabolism, resulting in low plasma levels of MTP, which would explain the inter-individual differences in NAFLD (Di Filippo et al., 2012). Subgroup analysis using genotyping methods and based on sample size revealed that the MTP $-493 \mathrm{G}>\mathrm{T}$ polymorphism was associated with an increased risk of NAFLD in the PCR-RFLP and large sample-size subgroups, but not in the non-PCR-RFLP and small sample-size subgroups. However, these disparate results may be related to the small sample size, which can result in substantial statistical errors (Serre et al., 2008). Our findings were partially consistent with previous studies demonstrating that genetic variation in the MTP gene may confer susceptibility to NAFLD, suggesting that the MTP $-493 \mathrm{G}>$ T polymorphism is promising as a biomarker for the early diagnosis of NAFLD.

Although this is the first meta-analysis focusing on the relationships between the MTP genetic polymorphism and the risk of NAFLD, there were some limitations to our study. First, our results lacked sufficient statistical power to assess the correlations between the MTP genetic polymorphism and susceptibility to NAFLD because of the relatively small sample size. Second, this meta-analysis was a retrospective study that may lead to subject selection bias, thereby affecting the reliability of our results. Third, we were unable to obtain original data from the included studies, which may limit further evaluation of the potential roles of MTP genetic polymorphism in the development and progression of NAFLD. Importantly, the inclusion criteria of cases and controls were not well-defined in all included studies, which may also have influenced our results. 
In conclusion, our meta-analysis suggests that the MTP $-493 \mathrm{G} / \mathrm{T}$ polymorphism contributes to the development of NAFLD. Thus, the MTP $-493 \mathrm{G} / \mathrm{T}$ polymorphism is a potential biomarker for the early detection of NAFLD. However, further detailed studies are required to support our findings.

\section{Conflicts of interest}

The authors declare no conflict of interest.

\section{ACKNOWLEDGMENTS}

Research supported by the Foundation of Scientific Research of Education Department of Liaoning Province (\#05L566). We would also like to thank all of our colleagues working in the Department of Emergency, the Fourth Affiliated Hospital of China Medical University.

\section{REFERENCES}

Alisi A, Cianfarani S, Manco M, Agostoni C, et al. (2012). Non-alcoholic fatty liver disease and metabolic syndrome in adolescents: pathogenetic role of genetic background and intrauterine environment. Annals Med. 44: 29-40.

Carulli L, Canedi I, Rondinella S, Lombardini S, et al. (2009). Genetic polymorphisms in non-alcoholic fatty liver disease: interleukin-6-174G/C polymorphism is associated with non-alcoholic steatohepatitis. Dig. Liver Dis. 41: 823-828.

Day CP (2006). Genes or environment to determine alcoholic liver disease and non-alcoholic fatty liver disease. Liver Int. 26: $1021-1028$.

Day CP (2010). Genetic and environmental susceptibility to non-alcoholic fatty liver disease. Dig. Dis. 28: 255-260.

Di Filippo M, Créhalet H, Samson-Bouma ME, Bonnet V, et al. (2012). Molecular and functional analysis of two new MTTP gene mutations in an atypical case of abetalipoproteinemia. J. Lipid Res. 53: 548-555.

Dongiovanni P, Valenti L, Rametta R, Daly A, et al. (2010). Genetic variants regulating insulin receptor signalling are associated with the severity of liver damage in patients with non-alcoholic fatty liver disease. Gut 59: 267-273.

Dowman JK, Tomlinson JW and Newsome PN (2010). Pathogenesis of non-alcoholic fatty liver disease. QJM 103: 71-83.

Duvnjak M, Barsić N, Tomasić V and Lerotić I (2009). Genetic polymorphisms in non-alcoholic fatty liver disease: clues to pathogenesis and disease progression. World J. Gastroenterol. 15: 6023-6027.

El-Koofy NM, El-Karaksy HM, Mandour IM, Anwar GM, et al. (2011). Genetic polymorphisms in non-alcoholic fatty liver disease in obese Egyptian children. Saudi J. Gastroenterol. 17: 265-270.

Fan JG and Farrell GC (2009). Epidemiology of non-alcoholic fatty liver disease in China. J. Hepatol. 50: 204-210.

Fon Tacer K and Rozman D (2011). Nonalcoholic Fatty liver disease: focus on lipoprotein and lipid deregulation. J. Lipids 2011: 783976.

Gambino R, Cassader M, Pagano G, Durazzo M, et al. (2007). Polymorphism in microsomal triglyceride transfer protein: a link between liver disease and atherogenic postprandial lipid profile in NASH? Hepatology 45: 1097-1107.

Hashemi M, Hoseini H, Yaghmaei P, Moazeni-Roodi A, et al. (2011). Association of polymorphisms in glutamatecysteine ligase catalytic subunit and microsomal triglyceride transfer protein genes with nonalcoholic fatty liver disease. DNA Cell. Biol. 30: 569-575.

Hussain MM, Rava P, Walsh M, Rana M, et al. (2012). Multiple functions of microsomal triglyceride transfer protein. Nutr. Metab. 9: 14.

Liu Q, Bengmark S and Qu S (2010). The role of hepatic fat accumulation in pathogenesis of non-alcoholic fatty liver disease (NAFLD). Lipids Health Dis. 9: 42.

Malaguarnera M, Di Rosa M, Nicoletti F and Malaguarnera L (2009). Molecular mechanisms involved in NAFLD progression. J. Mol. Med. 87: 679-695.

Mirandola S, Osterreicher CH, Marcolongo M, Datz C, et al. (2009). Microsomal triglyceride transfer protein polymorphism $(-493 \mathrm{G} / \mathrm{T})$ is associated with hepatic steatosis in patients with chronic hepatitis C. Liver Int. 29: 557-565.

Musso G, Gambino R and Cassader M (2010). Lipoprotein metabolism mediates the association of MTP polymorphism with beta-cell dysfunction in healthy subjects and in nondiabetic normolipidemic patients with nonalcoholic 
steatohepatitis. J. Nutr. Biochem. 21: 834-840.

Musso G, Gambino R, De Michieli F, Biroli G, et al. (2007). Nitrosative stress predicts the presence and severity of nonalcoholic fatty liver at different stages of the development of insulin resistance and metabolic syndrome: possible role of vitamin A intake. Am. J. Clin. Nutr. 86: 661-671.

Namikawa C, Shu-Ping Z, Vyselaar JR, Nozaki Y, et al. (2004). Polymorphisms of microsomal triglyceride transfer protein gene and manganese superoxide dismutase gene in non-alcoholic steatohepatitis. J. Hepatol. 40: 781-786.

Oliveira CP, Stefano JT, Cavaleiro AM, Zanella Fortes MA, et al. (2010). Association of polymorphisms of glutamatecystein ligase and microsomal triglyceride transfer protein genes in non-alcoholic fatty liver disease. J. Gastroenterol. Hepatol. 25: 357-361.

Pagano C, Soardo G, Esposito W, Fallo F, et al. (2005). Plasma adiponectin is decreased in nonalcoholic fatty liver disease. Eur. J. Endocrinol. 152: 113-118.

Patton HM, Yates K, Unalp-Arida A, Behling CA, et al. (2010). Association between metabolic syndrome and liver histology among children with nonalcoholic fatty liver disease. Am. J. Gastroenterol. 105: 2093-2102.

Pereira IV, Stefano JT and Oliveira CP (2011). Microsomal triglyceride transfer protein and nonalcoholic fatty liver disease. Expert Rev. Gastroenterol. Hepatol. 5: 245-251.

Peters JL, Sutton AJ, Jones DR, Abrams KR, et al. (2006). Comparison of two methods to detect publication bias in metaanalysis. JAMA 295: 676-680.

Petit JM, Masson D, Minello A, Duvillard L, et al. (2006). Lack of association between microsomal triglyceride transfer protein gene polymorphism and liver steatosis in HCV-infected patients. Mol. Genet. Metab. 88: 196-198.

Poniachik J, Csendes A, Díaz JC, Rojas J, et al. (2006). Increased production of IL-1 $\alpha$ and TNF- $\alpha$ in lipopolysaccharidestimulated blood from obese patients with non-alcoholic fatty liver disease. Cytokine 33: 252-257.

Postic C and Girard J (2008). The role of the lipogenic pathway in the development of hepatic steatosis. Diabetes Metab. 34: 643-648.

Serre D, Montpetit A, Paré G, Engert JC, et al. (2008). Correction of population stratification in large multi-ethnic association studies. PLoS One 3: e1382.

Shimabukuro M, Higa M, Yamakawa K, Masuzaki H, et al. (2013). Miglitol, $\alpha$-glycosidase inhibitor, reduces visceral fat accumulation and cardiovascular risk factors in subjects with the metabolic syndrome: a randomized comparable study. Int. J. Cardiol. 167: 2108-2113.

Siqueira ER, Oliveira CP, Correa-Giannella ML, Stefano JT, et al. (2012). MTP -493G/T gene polymorphism is associated with steatosis in hepatitis C-infected patients. Braz. J. Med. Biol. Res. 45: 72-77.

Stang A (2010). Critical evaluation of the Newcastle-Ottawa scale for the assessment of the quality of nonrandomized studies in meta-analyses. Eur. J. Epidemiol. 25: 603-605.

Sugihara T, Koda M, Kishina M, Kato J, et al. (2013). Fatty liver Shionogi-ob/ob mouse: A new candidate for a nonalcoholic steatohepatitis model. Hepatol. Res. 43: 547-556.

Sun Y, Lian Z, Jiang C, Wang Y, et al. (2012). Beneficial metabolic effects of 2',3',5'-tri-acetyl-N6- (3-hydroxylaniline) adenosine in the liver and plasma of hyperlipidemic hamsters. PLoS One 7: e32115.

Tannapfel A, Denk H, Dienes HP, Langner C, et al. (2011). Histopathological diagnosis of non-alcoholic and alcoholic fatty liver disease. Virchows Arch. 458: 511-523.

Wong VW, Wong GL, Yip GW, Lo AO, et al. (2011). Coronary artery disease and cardiovascular outcomes in patients with non-alcoholic fatty liver disease. Gut 60: 1721-1727.

Yoneda M, Iwasaki T, Fujita K, Kirikoshi H, et al. (2007). Hypoadiponectinemia plays a crucial role in the development of nonalcoholic fatty liver disease in patients with type 2 diabetes mellitus independent of visceral adipose tissue. Alcohol Clin. Exp. Res. 31: S15-S21.

Yoon D, Lee SH, Park HS, Lee JH, et al. (2005). Hypoadiponectinemia and insulin resistance are associated with nonalcoholic fatty liver disease. J. Korean Med. Sci. 20: 421-426.

Zampino R, Ingrosso D, Durante-Mangoni E, Capasso R, et al. (2008). Microsomal triglyceride transfer protein (MTP) $-493 \mathrm{G} / \mathrm{T}$ gene polymorphism contributes to fat liver accumulation in HCV genotype 3 infected patients. J. Viral Hepat. 15: 740-746.

Zintzaras E and Ioannidis JP (2005). HEGESMA: genome search meta-analysis and heterogeneity testing. Bioinformatics 21: 3672-3673. 